\title{
Silyl-protective groups influencing the reactivity and selectivity in glycosylations
}

\author{
Mikael Bols ${ }^{*}$ and Christian Marcus Pedersen ${ }^{*}$
}

\author{
Review \\ Address: \\ Department of Chemistry, University of Copenhagen, \\ Universitetsparken 5, 2100 Copenhagen, Denmark \\ Email: \\ Mikael Bols* - bols@chem.ku.dk; Christian Marcus Pedersen* - \\ cmp@chem.ku.dk \\ * Corresponding author \\ Keywords: \\ Carbohydrate; conformation; glycosylation; reactivity; selectivity
}

Beilstein J. Org. Chem. 2017, 13, 93-105.

doi:10.3762/bjoc. 13.12

Received: 10 August 2016

Accepted: 23 December 2016

Published: 16 January 2017

This article is part of the Thematic Series "The glycosciences".

Guest Editor: A. Hoffmann-Röder

(C) 2017 Bols and Pedersen; licensee Beilstein-Institut. License and terms: see end of document.

\begin{abstract}
Silyl groups such as TBDPS, TBDMS, TIPS or TMS are well-known and widely used alcohol protective groups in organic chemistry. Cyclic silylene protective groups are also becoming increasingly popular. In carbohydrate chemistry silyl protective groups have frequently been used primarily as an orthogonal protective group to the more commonly used acyl and benzyl protective groups. However, silyl protective groups have significantly different electronic and steric requirements than acyl and alkyl protective groups, which particularly becomes important when two or more neighboring alcohols are silyl protected. Within the last decade polysilylated glycosyl donors have been found to have unusual properties such as high (or low) reactivity or high stereoselectivity. This mini review will summarize these findings.
\end{abstract}

\section{Introduction}

Silicon-based protective groups of alcohols have a long history in organic chemistry [1-3]. The most popular and commercially available silyl-protective groups are trimethylsilyl (TMS), triethylsilyl (TES), tert-butyldimethylsilyl (TBS), tert-butyldiphenylsilyl (TBDPS), triisopropylsilyl (TIPS) as well as the diol-protective groups DTBS and TIPDS (Figure 1). Silyl groups have also early been used in the carbohydrate field to provide an alternative orthogonal protective group to the more conventional acetyl, benzoyl and benzyl groups. Particularly in oligosaccharide synthesis where many orthogonal hydroxy protective groups are required silicon protective groups have frequently been introduced in both glycosyl donors and acceptors. However, glycosylation with heavily silylated carbohydrate derivatives is comparatively new, and so is the significance that silyl groups have on the stereoselectivity and reactivity in glycosylation reactions [4]. These findings, which most have occurred in the last decade, will be reviewed here.

\section{Review}

One of the earliest glycosylations with a persilylated glycosyl donor was carried out by Kihlberg and Broddefalk who needed an acid-labile protective group [5]. They protected a thiocresyl 
<smiles>[R][Si]([R])([R])OC</smiles>

TMS: $\mathrm{R}=\mathrm{CH}_{3}$

TES: $\mathrm{R}=\mathrm{CH}_{3} \mathrm{CH}_{2}$

TIPS: $\mathrm{R}=\left(\mathrm{CH}_{3}\right)_{2} \mathrm{CH}$<smiles>[R][Si]([R1])([R])OC</smiles>

TBS: $\mathrm{R}^{1}=\mathrm{CH}_{3} ; \mathrm{R}^{2}=t-\mathrm{Bu}$

TBDPS: $\mathrm{R}^{1}=\mathrm{Ph} ; \mathrm{R}^{2}=t-\mathrm{Bu}$
$t-\mathrm{Bu}_{4} \mathrm{O}^{\prime}$
$t-\mathrm{Bu}^{\prime \prime \prime} \mathrm{S}_{\mathrm{O}}^{\mathrm{O}}$

DTBS<smiles>CO[Si](OC)(O[Si](OC)(C(C)C)C(C)(C)C)C(C)(C)C</smiles>

TIPDS

Figure 1: Silicon-protective groups typically used in carbohydrate chemistry.

glucoside with TBS groups, oxidized the sulfur to sulfoxide 1 and used the latter to glucosylate the $2-\mathrm{OH}$ of the galactose derivative 2 (Scheme 1). The reaction gave a $56 \%$ yield of 3 as a 1:1 mixture of $\alpha$ - and $\beta$-glucosides. Migration of a TBS group to the acceptor alcohol 2 was observed as a byproduct (10\%). Attempts of glycosylating $\mathbf{2}$ with the thioglycoside or the corresponding glycosyl halides were unsuccessful. NMR studies of $\mathbf{1}$ revealed that the compound adopted a skew-boat conformation, based on the small ${ }^{3} J$ coupling constants, as well as long range w-couplings. This conformational flip is induced by the presence of the bulky trans-vicinal silyl groups [6].

Also with the purpose of having acid-labile protective groups on the donor a TES-protected trichloroacetimidate of fucose, $\mathbf{4}$, was employed by Myers et al. [7] in order to have protective groups compatible with their synthesis of neocarzinostatin. It was found that optimal glycosylation was performed with TMSOTf as a catalyst at low temperature and excess donor in diethyl ether since this gave the best $\alpha$-selectivity (Scheme 2). Using other protective groups on the fucose part, such as 2,3-
TIPDS and 4-O-TES led to glycosylation with only poor stereoselectivity [8]. The TES groups were also used successfully on the 2-methylamino analogue of 4 .

A glycosylation with a TES-protected glycosyl donor has also been performed in a case where the target contained a 6-O-acylglucoside and hence protective groups that could be removed under mild acidic conditions were needed [9]. This was for example used for the synthesis of the serine protease inhibitor banyaside. TES-protected glycosylimidates were also employed in the synthesis of antitumor saponins which contained partially acylated oligosaccharides. The TES groups could be removed by comparatively mild treatment with fluoride without hydrolysis or migration of $O$-acyl groups [10]. This strategy has also been applied to prepare partially acylated cholestan glycosides. In this case an imidate with a $2-O$-acetate and 3,4$O$-TES protection was used, which ensured stereoselectivity by neighboring-group participation [11]. For similar reasons the per-TES-protected thioglycoside 7 was employed to prepare the Lewis X trisaccharide: The reaction of 7 with disaccharide 8

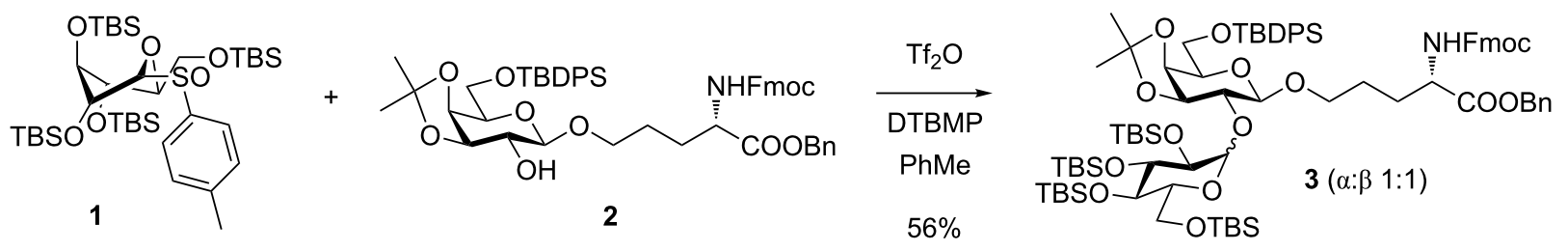

Scheme 1: Glycosylation with sulfoxide 1.

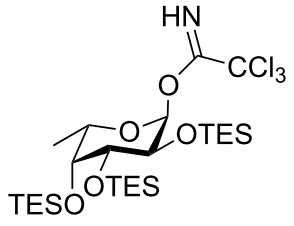

4<smiles>CC(=O)O[C@H]1C=C[C@@H](O)C1</smiles>

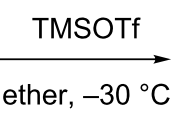

$95 \%$

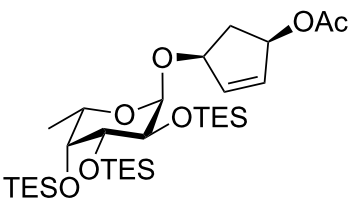

$6(\alpha: \beta$ 11:1) 
promoted by dimethyl disulfide and triflic anhydride gave trisaccharide 9 with high $\alpha$-selectivity (Scheme 3) [12]. These conditions, using this promoter system, worked fine in a number of similar cases.

The less-stable trimethylsilyl group has been employed by Gervay-Hague and co-workers to protect glycosyl donors [1317]. The reaction of a hexa-TMS-protected lactose derivative $\mathbf{1 0}$ with TMS iodide converted it to glycosyl iodide $\mathbf{1 1}$ that glycosylated alcohols in good yields (Scheme 4). The TMS protective groups are however rather unstable and they were exchanged to acetyl groups after the glycosylation step [13] Nevertheless, the TMS-protected glycosyl iodides were useful intermediates because they were more reactive and less prone to elimination than the corresponding benzylated or acetylated glycosyl iodides.

\section{Effect of silyl protective groups on the reactivity}

Protective groups can profoundly influence the reactivity of carbohydrate derivatives and especially glycosyl donors [18]. This influence is due to the different electron-withdrawing capability of protective groups. During the glycosylation reaction the anomeric carbon becomes increasingly electron poor, with the formation of a glycosyl cation as the extreme. This development of a (partial) positive charge is less favorable with more EWD protective groups and the reaction becomes slower; i.e., the donor is less reactive (disarmed) [19]. Ester protective groups such as acetyl and benzoyl are among the most electronwithdrawing of the common protective groups, whereas benzyl (or methyl) groups are less so, which is reflected in the reactivity of glycosyl donors carrying these groups. As shown in Figure 2, the thioglycoside with benzyl ethers $\mathbf{1 3}$ is about

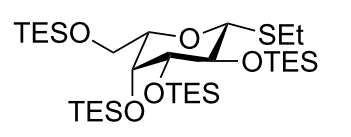

7

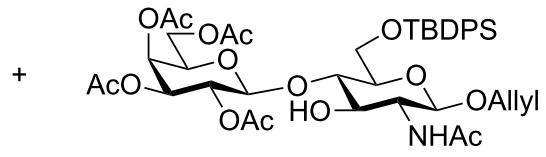

8

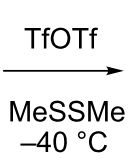

$53 \%$

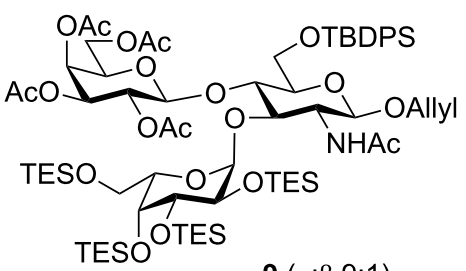

$9(\alpha: \beta 9: 1)$

Scheme 3: Glycosylation with thioglycoside 7.

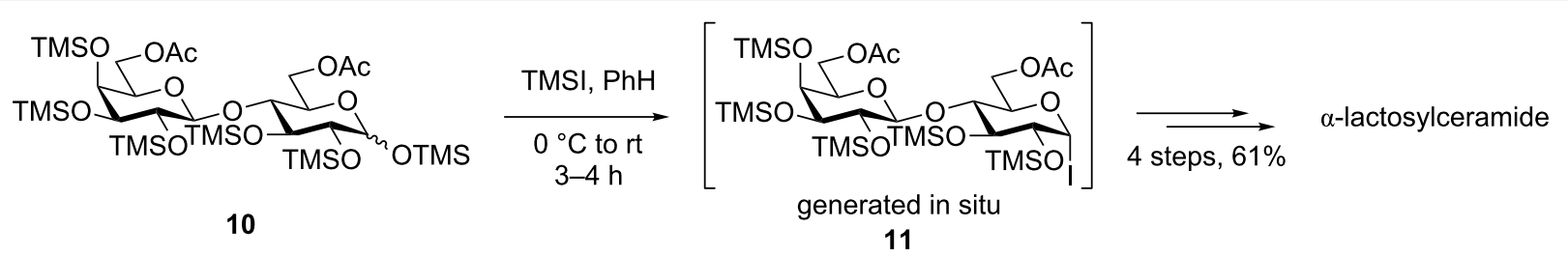

Scheme 4: In situ formation of a silylated lactosyl iodide for the synthesis of $\alpha$-lactosylceramide.

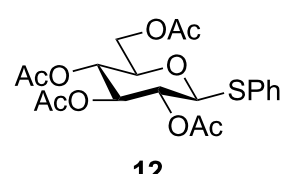

12

relative reactivity

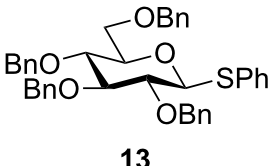

39

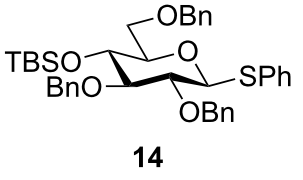

102

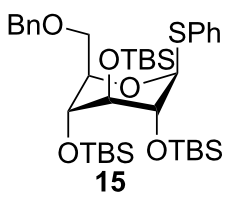

758

base strength

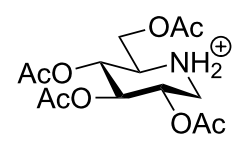

16

$\mathrm{p} K_{\mathrm{a}} 3.5$

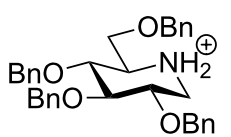

17

$\mathrm{p} K_{\mathrm{a}} 6.0$

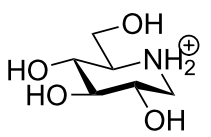

18

$\mathrm{p} K_{\mathrm{a}} 6.7$
TBSO
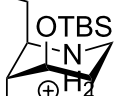

OTBS OTBS

19

$\mathrm{p} K_{\mathrm{a}} 8.5$

Figure 2: Comparison of the reactivity of glycosyl donors with the $\mathrm{p} K_{\mathrm{a}}$ of the corresponding piperidinium ions. 
40 times more reactive towards glycosylation with methanol upon activation by NIS, than the acetylated counterpart $\mathbf{1 2}$, but the thioglycosides with silyl ethers are even more reactive [20].

Thus the presence of a single $O$-TBS group (14) can more than double the reactivity while three (15) will increase the rate by 20 times as compared to benzyl. The increased reactivity of the silylated glycosyl donors is partially due to the $O$-silyl group being somewhat less electron withdrawing than the benzyl, but also due to the ability of bulky silyl groups to cause a change in the sugar ring conformation [21]. The influences of the various protective groups are also clearly reflected in their ability to alter the base strength of the transition state mimicking amine deoxynojirimycin (Figure 2) [22]. The acetylated amine $\mathbf{1 6}$ is vastly less basic than the benzylated analogue $\mathbf{1 7}$, which is still less basic than the unprotected amine $\mathbf{1 8}$ which in many ways should be similar to an O-silylated compound 19 since the silyl group inductively is very comparable to the proton. Yet the silylated amine $\mathbf{1 9}$ is almost a 100 times more basic due to the conformational ring flipping induced by the bulky silyl groups. This extraordinary effect on the basicity and the donor reactivity stems from the conformational change in the sugar ring, which causes the OR groups in the 3 and 4 and occasionally the 2-position to adopt an (pseudo)axial orientation, which is less electron withdrawing [23]. This conformational change is induced when having trans-vicinal OR groups (Figure 3). Normally the bisequatorial orientation is preferable due to 1,3diaxial interactions of axial substituents. This steric interaction can however be overridden when the $\mathrm{R}$ groups are sufficient bulky and hence the sugar ring changes the conformation. The electronegativity of the $\mathrm{R}$ group is probably also important;

$\beta$-glucosyl donor:
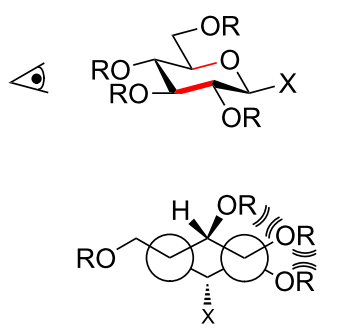
$\mathrm{R}=\mathrm{Bn}, \mathrm{Ac}, \mathrm{Bz}$ etc. all equatorial ${ }^{4} \mathrm{C}_{1}$
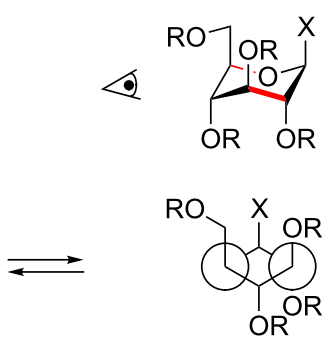

$\mathrm{R}=\mathrm{TBS}, \mathrm{TIPS}, \mathrm{TBDPS}$

all axial or axial rich ${ }^{1} C_{4}\left(\right.$ or $\left.^{3} S_{1}\right)$
Figure 3: Conformational change induced by bulky vicinal protective groups such as TBS, TIPS and TBDPS. The vicinal clash overrules the 1,3-diaxial interaction, which is less influenced by bulky silyl ethers as these can rotate more freely in the axial-rich conformation. The projections are along the red bonds in the two models. when more electropositive (as $\mathrm{Si}$ ), the oxygen atoms become more electron rich and their repulsion becomes larger.

Changing the conformation of a heterocycle has, as mentioned, been studied using the piperidine model system. The $\mathrm{p} K_{\mathrm{a}}$ of the corresponding piperidinium ion is a measure of the stereoelectronic effects and correlates with the glycosyl donor's reactivity observed. Forcing an OR group from an equatorial position into an axial position by, e.g., a bulky silyl group, increases the basicity of the piperidines, which is analogous to increasing the reactivity of the corresponding glycosyl donors.

The increased reactivity is very clearly displayed when TBS or TIPS-protected thioglycosyl donors are mixed with benzylated thioglycoside acceptors under activating conditions (Table 1). The benzylated thioglycosides $\mathbf{2 1}$ and 26, normally termed 'armed' due to their comparatively high reactivity, were selectively glycosylated by silylated thioglycosides (20, 23, 25, 28 and 30) in high yield without any self-glycosylation of the armed donors $[24,25]$. Based on their extraordinary reactivity these silylated donors were termed 'superarmed'. The listed reactions (Table 1) were all highly stereoselective as well. The stereoselectivity is very dependent on the bulkiness of the protective group on C2 in the mannosyl (28), rhamnosyl (23 and 30) and glucosyl donors (20) (see also Scheme 11). In these systems the trans products are favored. In the galactosyl donor 25 the bulky $\mathrm{C} 4$ substituent shields the $\beta$-face of the donor and hence the glycosylation is very $\alpha$-selective.

The remarkable difference in reactivity between disarmed, armed and superarmed donors 20, 26 and 32, respectively was used for "one-pot one addition" glycosylations having all 3 donors present together with all reagents from the start (Scheme 5). The activation of the individual donors was controlled by changing the temperature and the trisaccharide donor 33 could thereby be prepared in excellent yields [21].

The reactivity of silylated donors have also been investigated by Hung, Wong and collaborators [26]. Investigating benzylated thioglucosides with a single or two TBS or TIPS groups in different positions they observed an increasing rate that were qualitatively similar to those described in Figure 2. Rate increases were however larger and TIPS protection had a greater rate-increasing effect than TBS protection.

The rate increases caused by a single silyl group in the 2,3 and 4-position are particular remarkable given that no obvious conformational change in the ground state is observed. Thus the increased rate must be caused by the group's ability to favor conformational inversion to the more reactive axial conformation in the transition state. This explains the comparatively large rate 
Table 1: Reaction of silylated thioglycosides with benzylated thioglycoside acceptors.

(y)

aOnly the shown stereoisomer was obtained. Data taken from [24,25].

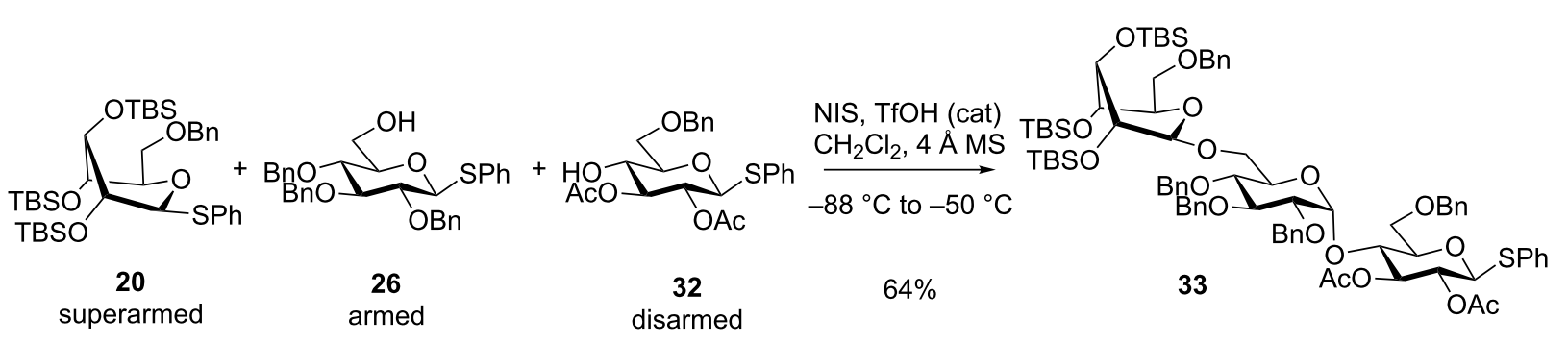

Scheme 5: An example of a "one pot one addition" glycosylation, where 3 glucosyl donors are mixed with 2.1 equiv NIS and a catalytic amount of $\mathrm{TfOH}$. The individual donors are activated at different temperatures due to their reactivity and the trisaccharide donor is formed in an excellent yield.

enhancements observed by TBS and TIPS groups compared to unprotected $\mathrm{OH}$ and also that TIPS, which is more bulky than TBS, but essentially has the same inductive effect, causes a greater rate enhancement.

Gervay-Hague has reported that TMS-protected glycosyl iodides are remarkably more reactive than their benzyl-protected analogues $[13,27]$. While this rate enhancement is at least partially stemming from the change in the inductive effect, it is also possible that the comparatively more bulky TMS groups also cause an enhancing effect by favoring conformational inversion to the stereoelectronically more stable conformer in the transition state.

The reactivity of TBS-protected thioglycosides was further investigated by Scanlan and co-workers who made the fucosyl donor 34 (Scheme 6) [28]. Interestingly the NMR spectrum of this compound displayed line broadening indicating some con- 


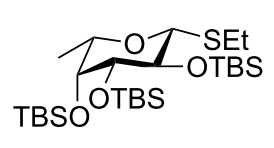

34

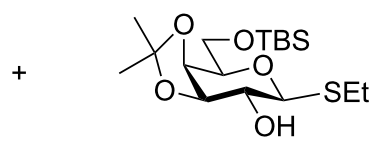

35

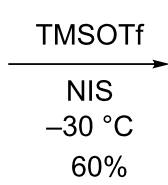

$60 \%$

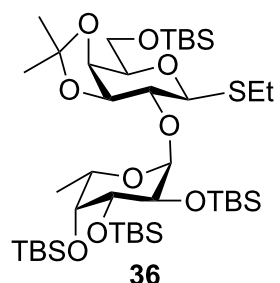

36

Scheme 6: Superarmed-armed glycosylation with thioglycoside 34.

formational inversion, but the X-ray structure of the crystalline compound was in the conventional ${ }^{1} C_{4}$ conformation. Yet the compound was clearly very reactive as it selectively could glycosylate the 2-OH of thioglycoside $\mathbf{3 5}$ giving $\mathbf{3 6}$ in a very good yield. Other acceptor alcohols were also glycosylated in a good yield and with high $\alpha$-selectivity [28].

Yang and co-workers have extended the concept to the furanoside series [29]. They showed that the arabinofuranosyl donor 37 and its 2-O-TBS analogue were more reactive than the corresponding benzylated thioglycosides in competition reactions and used the reactivity differences in a one-pot glycosylation reaction between $\mathbf{3 7}$, a disarmed donor/acceptor $\mathbf{3 8}$ and an acceptor 39, which gave the trisaccharide $\mathbf{4 0}$ in a remarkable yield of $88 \%$ (Scheme 7). This reaction works so well because the more readily activated donor 37 reacts with the more reactive and accessible primary alcohol of $\mathbf{3 8}$ rather than with the secondary hydroxy group in $\mathbf{3 9}$.
In the above study it was found that $\mathbf{3 7}$ was less reactive than the persilylated analogue [29], which was not obvious as the Demchenko group [30-35] has shown that a 2-O-ester can have an activating effect by the aid of anchimeric assistance [36]. This combination of conformational arming and anchimeric assistance was investigated by Heuckendorff et al., who studied the 2-O-benzoylated analogue of 20, 41 (Scheme 8) [37]. They observed that though $\mathbf{4 1}$ was less reactive than the 2-O-benzyl derivative $\mathbf{4 2}$ it was nevertheless more reactive than the conventionally armed donor and could smoothly be coupled on the 4-OH group of the armed thioglycoside $\mathbf{4 3}$ without competing self-condensation of $\mathbf{4 3}$.

The Yang group has also investigated superarmed galactothiofuranosides [38]. In line with the findings described above they found that the donor reactivity increased with the number of TBS protective groups in the molecule. However, the 3,5-di- $O$ TBS-2,6-di- $O$-benzoyl derivative was sufficiently reactive to

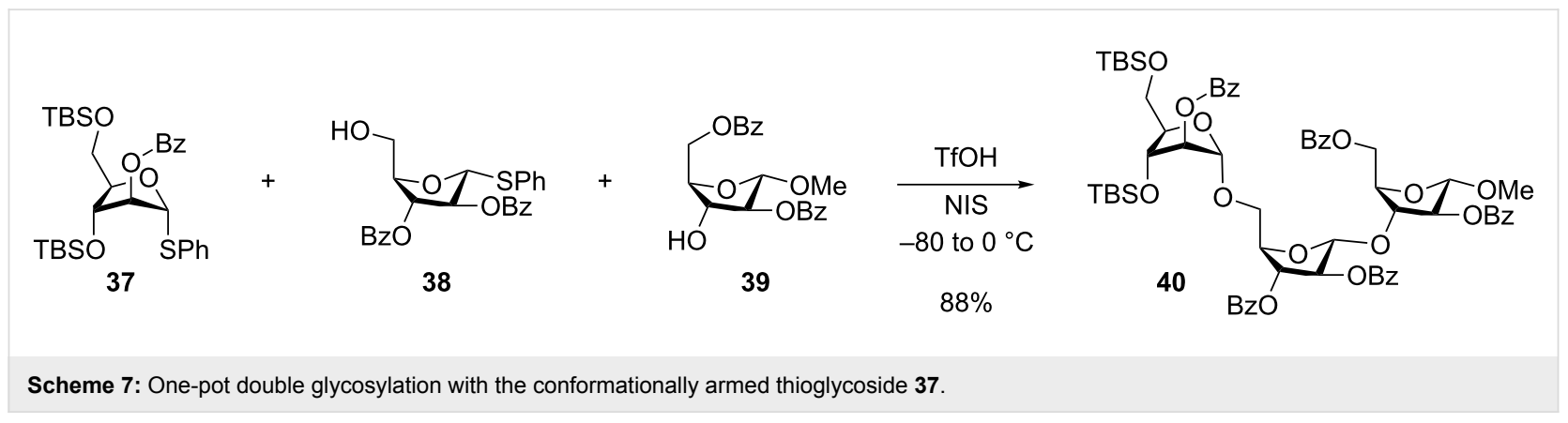

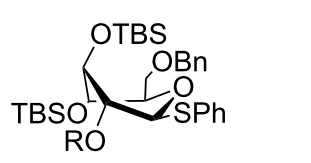

$41(\mathrm{R}=\mathrm{Bz})$

$42(\mathrm{R}=\mathrm{Bn})$

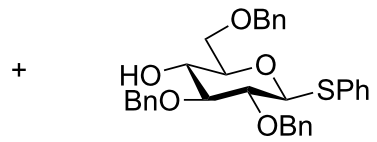

43

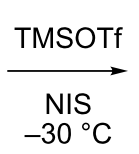

$70 \%$

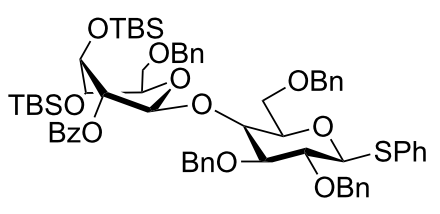

44 
glycosylate partially benzoylated thioglycosides with high chemoselectivity and was therefore used in a range of high yielding oligosaccharide syntheses [38].

The bifunctional silicon protective group DTBS (Figure 1) has been used both to increase and decrease the reactivity of glycosyl donors. The 4,6-O-DTBS-protected thioglucoside $\mathbf{4 5}$ was found to be much less reactive than $\mathbf{2 0}$ and only couples to armed donor/acceptors in low yield (Figure 4) [24]. This is analogous to the effect of the very similar benzylidene group, which is deactivating the donor partially due to locking the structure in an unreactive conformation and due to the electronic effect of a trans-gauche conformation of the hydroxymethyl group [22,39].

Yang and collaborators found that $\mathbf{4 6}$ was less reactive than the fully benzoylated analogue, which is obviously also due to the DTBS group locking the molecule into an unreactive conformation [29]. In line with this, the analogue of $\mathbf{4 6}$ having a TIPDS group rather than a DTBS was not particularly unreactive, as it is more flexible due to the bigger ring. The Yang group used 46 in a one-pot synthesis of a trisaccharide, where they took advantage of $\mathbf{4 6}$ being less reactive than partially benzoylated arabinofuranosides [29]. The concept was extended to the galactofuranosyl series, but was less useful there [38]. A slightly lower reactivity of $\mathbf{4 7}$ was found relative to the fully benzoylated species.

DTBS groups can also be used to increase the reactivity of glycosyl donors [40]. A series of differently configured monosaccharide thioglycosides were subjected to linking the 3 and 6-OH group together with this silyl ether. This forces the glycosyl-donor conformation to change into an axial-rich conformation and hence into a superarmed donor (Table 2) making it possible to glycosylate an armed glycosyl donor selectively. This approach works for glucosides, mannosides, and galactosides and both, $\alpha$ - and $\beta$-thioglycosides [40]. It was shown by competition experiments that these tethered donors were even

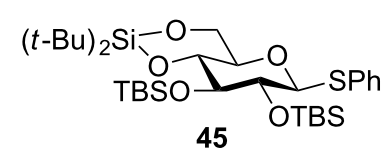

45

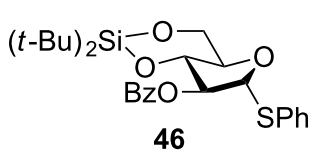

46

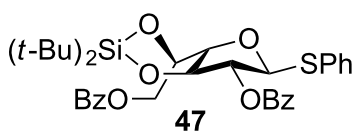

Figure 4: Donors disarmed by the di-tert-butylsilylene protective group.

Table 2: Reactions of 3,6-O-silyl-tethered thioglycosides.

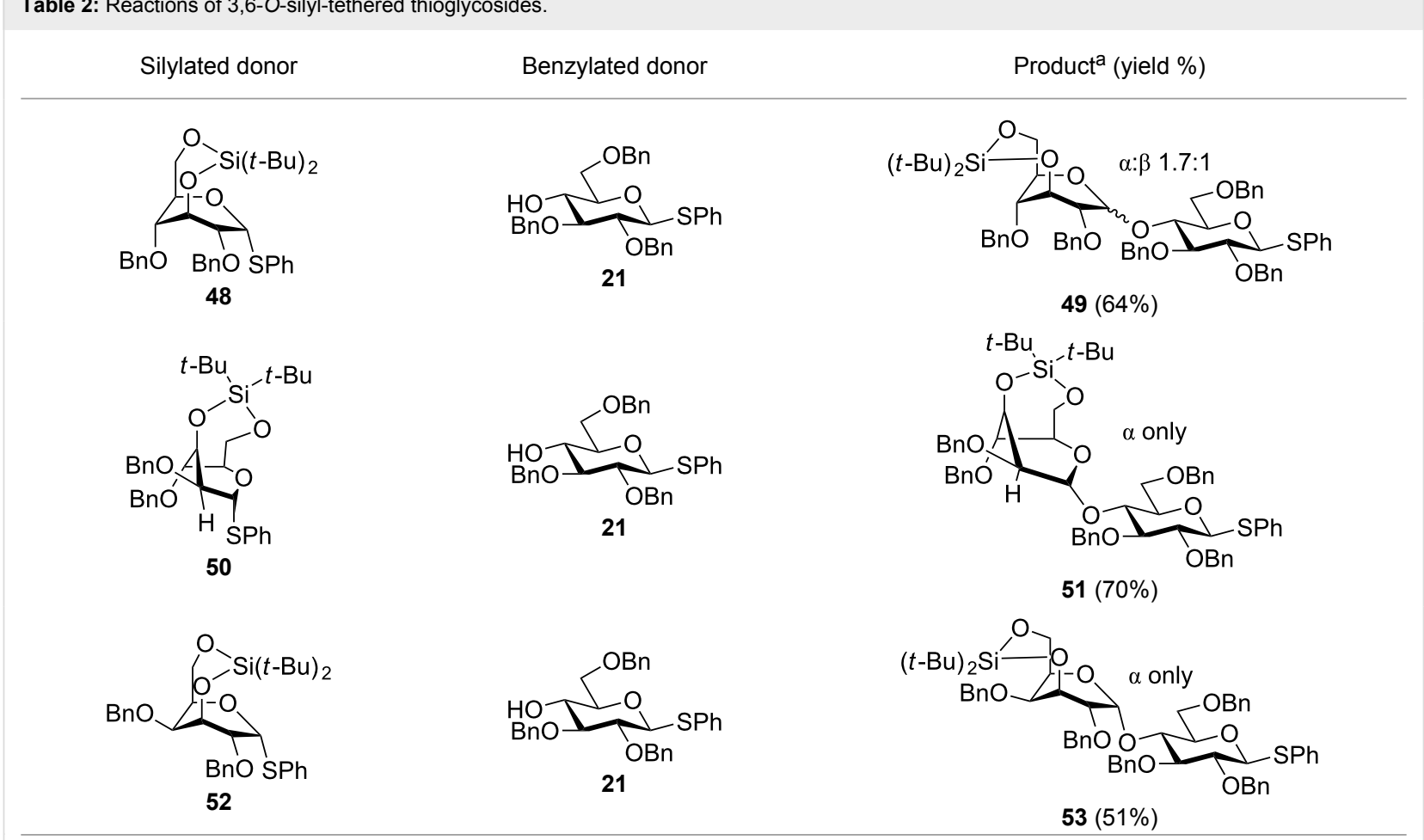

aOnly the shown stereoisomer was obtained. Data taken from [40]. 
more reactive than the TBS-protected donors such as $\mathbf{2 0}$. This was particularly the case for the $\alpha$-anomers as a considerable reactivity difference between $\alpha$ - and $\beta$-thioglucosides was observed with the $\alpha$-anomer consistently being more reactive. This suggested that the exact alignment of the leaving group is important for the reactivity, but a similar difference was not observed for other superarmed glycosyl donors (Figure 5).

Surprisingly, a 2,4-O-tethering of a glucosyl donor, giving the all axial conformation, did not increase the reactivity and the donor was found not to be superarmed. The explanation for this relates to the more strained conformation which counteracts a flattening of the conformation when approaching an $\mathrm{sp}^{2}$ hybridized $\mathrm{C} 1$ in the TS [41].

\section{Effect of silyl protective groups on the selectivity}

The bulkiness of TBS groups in donors such as $\mathbf{2 0}$ can have a significant influence on the diastereoselectivity. Thus glycosylations with 20 (Table 1) gave exclusively the $\beta$-glucoside presumably due to steric hindrance for attack from the $\alpha$-side $[24,42]$. The bulkiness of $\mathbf{2 0}$ was clearly seen in regioselective glycosylations performed by Felice et al. [43]. So, the glycosylation of the D-allo-configured acceptor $\mathbf{5 4}$ with $\mathbf{2 0}$ not only gave exclusively the $\beta$-glucoside, but resulted also in the glycosylation exclusively at the equatorial 4-OH group presumably due to the bulkiness of the silylated donor. Thus compound $\mathbf{5 5}$ (Scheme 9) was formed as the only product out of four possible isomers in 54\% yield. When the D-gluco-configured acceptor analogue of $\mathbf{5 4}$ was used, a mixture of regioisomers was obtained.

However, the ability of the bulky silyl groups to alter the conformation of the glycosyl-donor ring can be used to control the selectivity. Suzuki and collaborators showed that the $C$-arylation reactions with the 3,4-O-di(tert-butyldiphenylsilyl)-protected acetate $\mathbf{5 6}$ led to the $\alpha$-glycoside $\mathbf{5 8}$ with high selectivity (Scheme 10). The reason for this selectivity is that the equatorial position is more accessible for attack [44]. However, if different protective groups and even the related TBS group were

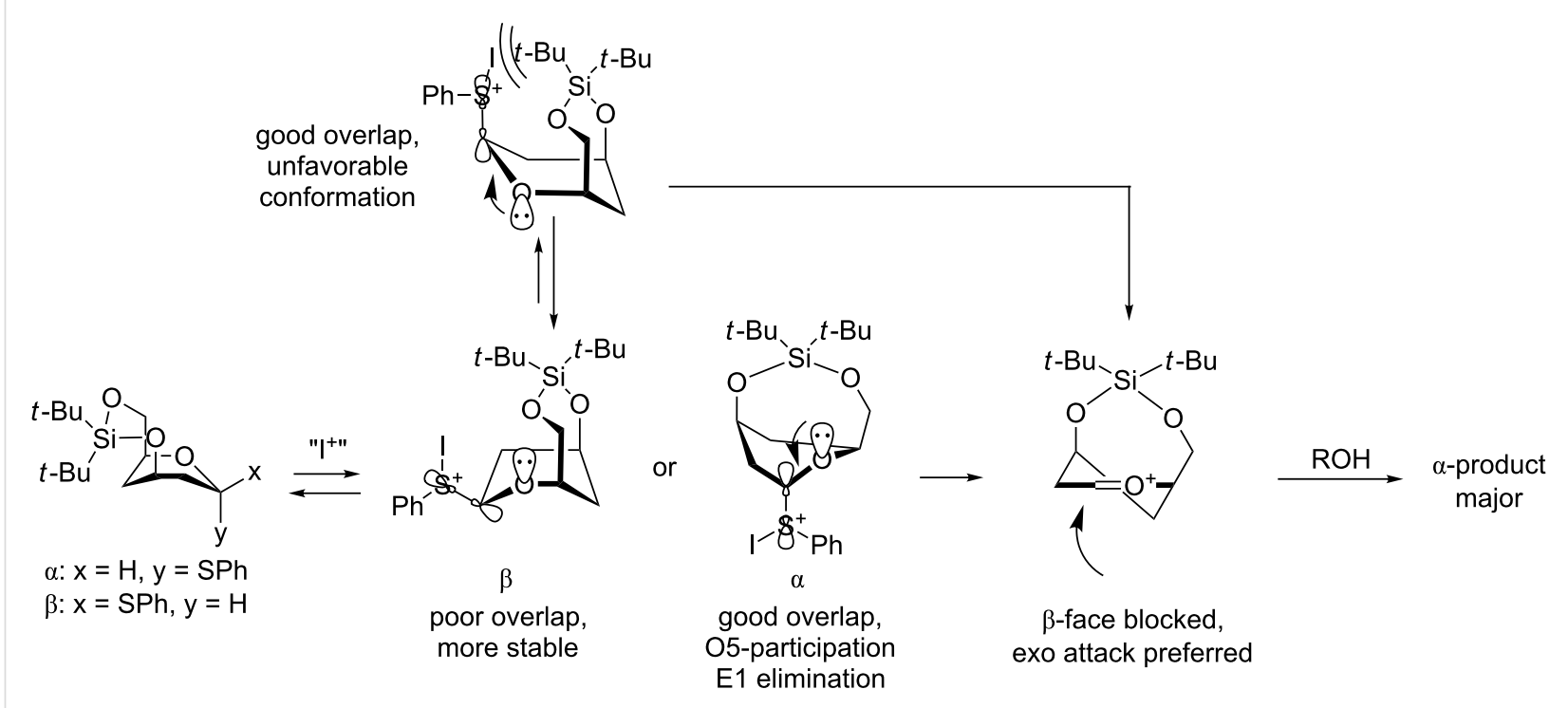

Figure 5: The influence of a 3,6-O-tethering on anomeric reactivity and glycosylation selectivity. The $\alpha$-thioglycoside is more reactive as a conformational change is not needed to expel the sulfonium ion. This is not the case with the $\beta$-anomer. Selectivity is mainly controlled by sterics and hence the $\alpha$-glycoside is kinetic product as the alcohol approach the oxocarbenium ion intermediate from the exo-side.

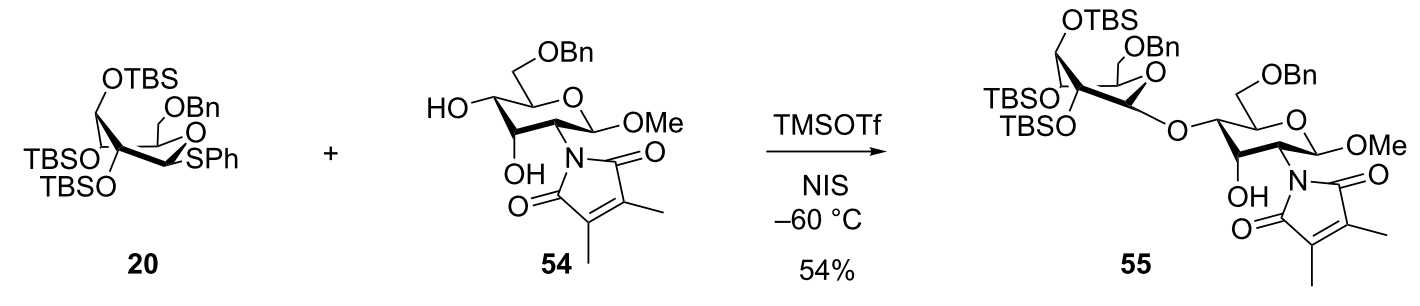

Scheme 9: Regio- and stereoselective glycosylation using the superarmed thioglycoside donor 20. 


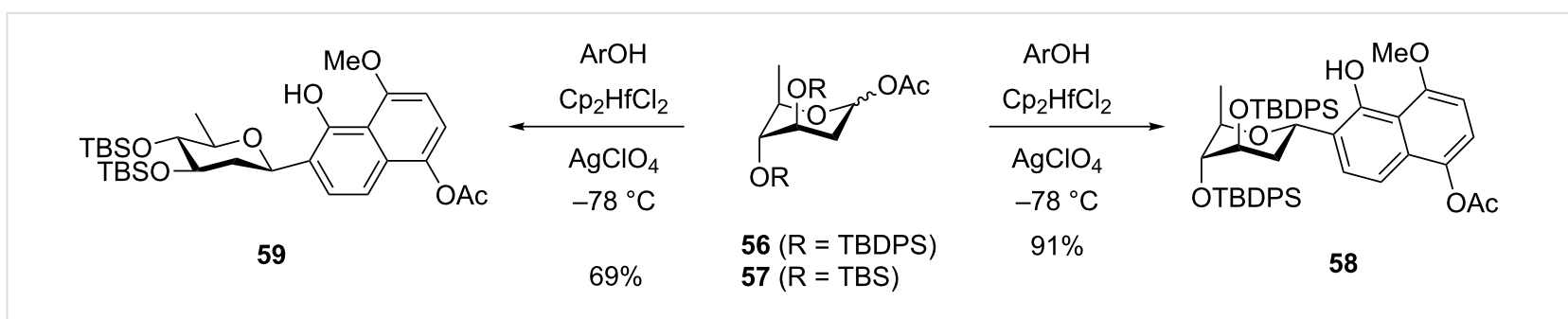

Scheme 10: Superarmed donors used for $C$-arylation and the dependence of the size of the silylethers on the stereochemical outcome.

used, predominantly the $\beta$-glycoside $\mathbf{5 9}$ was obtained in a 14:1 $\alpha: \beta$ ratio.

A similar conformation-controlled stereoselectivity has been demonstrated in radical reactions, however, with the twist that stereoselectivity here is opposite. The reduction of the selenoglycosides (analogues to 20) with tributyltin deuteride gave predominantly deuterium in the $\beta$-position for silylated derivatives in the ${ }^{1} C_{4}$ conformation, because the reaction intermediate is a radical that prefers to be axial. On the other hand, with acetate protective groups, the addition of deuterium occurred predominantly from the $\beta$-side $[45,46]$. The principle of conformational stereocontrol was also used for the stereoselective addition of carbon radicals $[46,47]$.

This selectivity has also been demonstrated for electrophilic additions to the anomeric position. Shuto and collaborators showed that, while 2,3,4-tri- $O$-benzylxylopyranosyl fluoride reacted with allyltrimethylsilane and $\mathrm{BF}_{3}$ to give a mixture of $\alpha$ and $\beta$-1- $C$-allyl xylosides, the 2,3,4-O-TBS-protected fluoride which is in ${ }^{1} C_{4}$ conformation, exclusively gave the $\beta$-xyloside. In contrast the xylosyl fluoride with a butane-2,3-bisacetal protective group, that keeps the conformation fixed in a ${ }^{4} C_{1}$ conformation, only gave the $\alpha$-xyloside [48]. This sort of behavior fits well with the reaction model proposed by Woerpel for these types of reactions [49].

Yamada and collaborators were the first to show that this principle could be used for the stereoselective synthesis of $O$-glycosides [42]. They prepared thioglucosides 60-62 (Scheme 11) having 2,3,4-O-TIPS groups and either TIPS, benzyl or pivaloyl protective groups on the 6 position. These glucosyl donors were found to adopt the ${ }^{3} S_{1}$ conformation and when they were reacted with methyl triflate and a glycosyl acceptor at room temperature they gave the $\beta$-glucosides in $45-92 \%$ yield and with $6: 1$ or better selectivity. The $6-O$ pivaloyl derivative 62 gave the best stereoselectivity (Scheme 11). The technique was later used in the synthesis of the natural product davidiin [50]. The 6-O-(3,5-diacetoxy-4-methoxy)benzoyl analogue of $\mathbf{6 2}$ was reacted with 3,5-diacetoxy-4-methoxybenzoic acid in the presence of methyl triflate, which gave the $\beta$-ester in $83 \%$ yield, showing that the principle works for ester synthesis, too.

The Yamada group also attempted to synthetize $\beta$-rhamnosides using this principle of conformational inversion [51]. The 3-OTBS-4-O-TBDPS-protected trichloroacetimidate 64 was investigated and could give $\beta$-selectivity up to $4: 1$ (Scheme 12). The corresponding thioglycoside donor gave an almost fifty-fifty selectivity. Experiments performed with the 3,4-O-TIPS-protected thiorhamnoside donors (Table 1) were not more successful as the activation of this donor with NIS/TfOH also gave mixtures and often predominantly the $\alpha$-rhamnoside [52]. This, together with the results with the $\alpha$-selective TBS-protected mannosyl and galactosyl donors (Table 1) [24], shows that there is no general trend with respect to the selectivity of these donors.

On the other hand, the configurationally inverted fully TBSprotected phenyl thiorhamnoside was found to be highly $\alpha$-selective (Table 1) presumably due to steric hindrance from

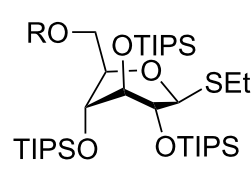

$62 \mathrm{R}=\mathrm{Piv}$

$61 \mathrm{R}=$ TIPS

$60 \mathrm{R}=\mathrm{Bn}$

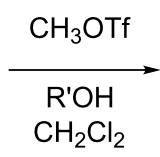

$25^{\circ} \mathrm{C}$

$82 \%(\alpha: \beta 1: 20)$

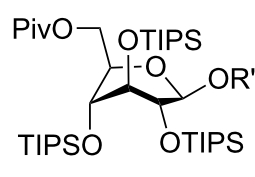

$63 \mathrm{R}^{\prime}=$ steroid

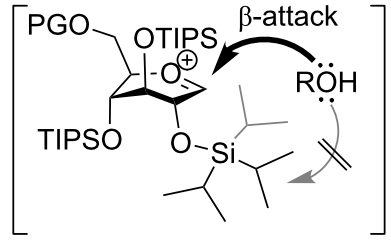




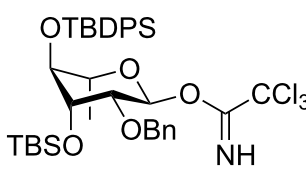

64

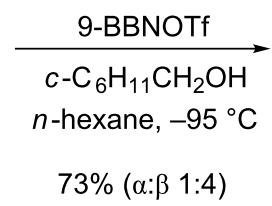

$73 \%(\alpha: \beta 1: 4)$

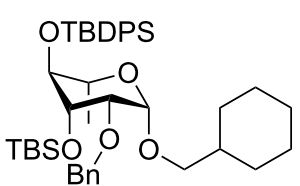

65

Scheme 12: $\beta$-Selective rhamnosylation with a conformationally inverted donor.

the 2-O-TBS on the $\beta$-face. This donor was recently used in the synthesis of glycosyltransferase acceptor substrates [53]. Yet the 2-O-TBS protection does not always have this effect. In a recent paper it was shown that in a 4,6-O-benzylidene-protected thioglucoside donor, which has been shown by Crich to be $\alpha$-selective, the $\alpha$-selectivity increased even more when a 2-O-benzyl was exchanged with 2-O-TBS or 2-O-TIPS [54]. The authors suggested that the silyl group had an inductive effect that favored $\alpha$-formation.

The 4,6- $O$-DTBS group has been shown to be an $\alpha$-directing group in galactosylation reactions. Kiso and co-workers found that the galactosyl donor $\mathbf{6 6}$ (Scheme 13) reacted with several different acceptor alcohols giving exclusively the $\alpha$-galactoside despite having a potentially $\beta$-directing benzoate group in the 2-position [55]. Thus the glycoside 68 was obtained in 74\% yield as the only isolated product (Scheme 13). Equally remarkable is that the corresponding DTBS-protected galactosamine donors (such as 67) displayed the same selectivity in the presence of the silyl group and thereby overriding the influence of a 2-phthalimido, $N$-Troc or $N$-Ac group. It was suggested that the bulky DTBS group is shielding the $\beta$-face and thereby preventing attack from that face of the oxocarbenium ion. This methodology has been applied to the synthesis of glycolipids and was shown to also work with 2-O-benzyl [56] or 2-O-TBS and with $N$-phenyltrifluoroacetimidate as the leaving group $[57,58]$. A somewhat similar influence has been observed with the much less steric demanding 4,6-O-benzylidene protective group [59].

A related stereoselectivity is induced by the DTBS group in arabinofuranosylations. Boons and collaborators found that the 3,5-DTBS-protected L-arabinosyl donor 69 upon reaction with acceptor 70 and activation with NIS/silver triflate gave exclusively the $\beta$-glycoside in a yield of $94 \%$ (Scheme 14 ).

Similarly, the reaction of $\mathbf{7 0}$ with the corresponding perbenzylated donor only gave a 2:1 $\beta: \alpha$-ratio of 71 [60]. It was proposed that the selectivity was caused by a favored $\beta$-attack on the oxocarbenium ion in an $E_{3}$ conformation as the corresponding $\alpha$-attack would lead to an unfavorable eclipsed conformation. The exchange of the 2-O-benzyl with a 2-O-TIPS leads to some

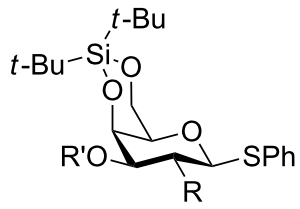

$66 \mathrm{R}=\mathrm{OBz}, \mathrm{R}^{\prime}=\mathrm{Bz}$

$67 \mathrm{R}=\mathrm{NHAc}, \mathrm{R}^{\prime}=\mathrm{Ac}$

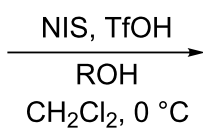

$74 \%(\alpha: \beta 1: 0)$

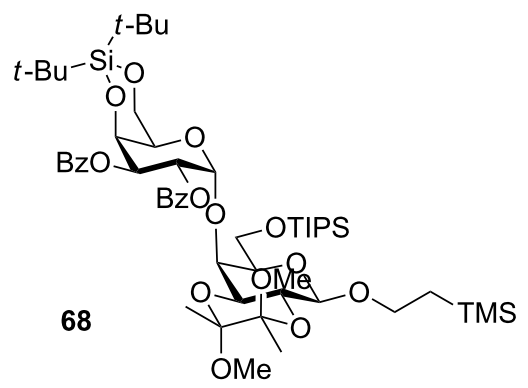

Scheme 13: a-Selective galactosylation with DTBS-protected galactosyl donors.<smiles>CC(C)(C)[Si](C)(C)OC1O[C@@H](Br)C2OCC1O2</smiles>

69

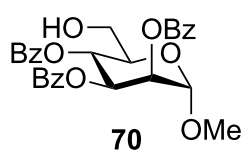

70

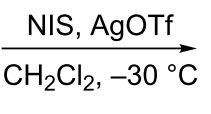

$94 \%(\alpha: \beta 0: 1)$

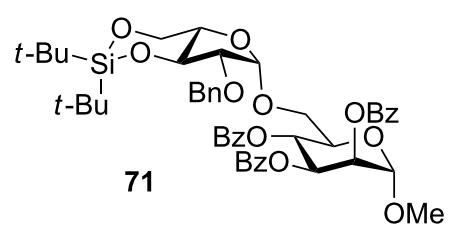


erosion of stereoselectivity though the donor was still highly $\beta$-selective [61]. Independently of the work by the Boons group, Crich et al. showed that using preactivation conditions on the equivalent $\mathrm{D}$-arabinofuranosyl donor resulted in rupture of the $\beta$-selectivity [62]. Ito and co-workers studied the influence of tethering the 3- and 5-OH by a 3,5-O-(tetraisopropyldisilylene)acetal and also found the arabinofuranolysations to be $\beta$-selective, despite the more flexible system [63]. Interestingly it was recently found that exchanging the 3,5-DTBS group with trifluoroacetates retained a high $\beta$-selectivity, which suggests that the stereoselectivity is also related to the deactivating properties of the protective group [64].

Cyclic silyl protective groups were also recently found to have a beneficial influence on the $\alpha$-selectivity obtained in glycosylations using glucals [65]. The reaction of 3,4-O-TIPDS-protected glucal $\mathbf{7 2}$ with acceptor alcohols such as 73, catalyzed by $p$-TsOH, gave exclusively $\alpha$-glucoside 74 (Scheme 15). When the same glycosylation was performed with the fully benzylated or TBS-protected glucal the reaction gave a lower yield and was accompanied by some formation of the $\beta$-anomer and some Ferrier rearrangement product. With donor 72 the reaction was however high yielding and exclusively $\alpha$-selective for a range of alcohols. Surprisingly the 6-deoxy version of $\mathbf{7 2}$ gave a lower $\alpha$-selectivity. The observations were explained with the assistance of DFT calculations as being due to the TS structure (formed from 72) being in an $\alpha$-selective ${ }^{4} H_{3}$ conformation with the 6-TIPS group in an electronically favored gauche-gauche conformation [66], that causes additional shielding from the $\beta$-face [65].

The influence of having a 2,4-O-di-tert-butylsilylene (DTBS) in a glucosyl donor was, as earlier mentioned, not increasing the reactivity of the donor, but it influences the selectivity in the glycosylation. The $\alpha$-site of the donor becomes the endo face, which results in an attack from the $\beta$-site. In a conventional glucosyl donor this leads to a 1:10 $\beta$-selectivity [41]. Recently this behavior has been used by Furukawa et al. in a $\beta$-controlled glucuronylation, where the bulky silylene in $\mathbf{7 5}$ ensures high selectivity without neighboring group participation (Scheme 16) [67].

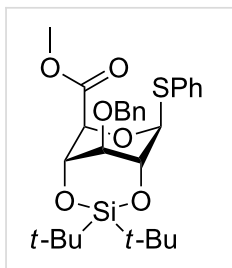

75

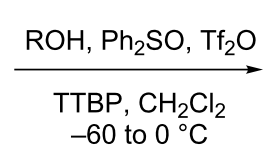

-60 to $0{ }^{\circ} \mathrm{C}$

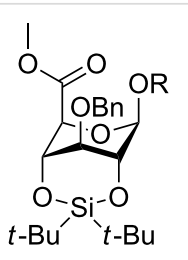

76

$\beta$ only
Scheme 16: Highly $\beta$-selective glucuronylation using a 2,4-DTBStethered donor.

\section{Conclusion}

Much indicates that glycosyl donors with silyl protective groups generally are more reactive than their alkylated counterparts presumably due to the $O$-silyl group being slightly less electron withdrawing than, e.g., a benzyl group. However, the reactivity increase is further augmented when bulky silyl groups, that cause a conformational change to an axial-rich conformation, are present. Such "superarmed" donors have a reactivity beyond what is obtained conventionally because the axial or pseudoaxial OR groups are less electron withdrawing. On the other hand, when the conformation is restricted by cyclic silyl protective groups (i.e., DTBS and TIPDS) and equatorial rich, comparatively unreactive donors result. Similarly, DTBS groups can be used to create superarmed donors by locking the conformation in an axial-rich state.

The silyl groups can also profoundly influence the stereoselectivity but in less obvious ways. Many TBS-protected donors are stereoselective - in some cases selectivities appear to be caused by steric hindrance from the 2-O-TBS group. For $C$-glycosides it has been possible to obtain conformationally derived stereocontrol so that persilylated donors adopting a ${ }^{1} C_{4}$ conformation give the $\beta$-products. However, for $O$-glycosylation, this type of selectivity has been difficult to achieve.

Some very useful stereoselectivities are obtained with DTBS and TIPDS-protected galactosyl, mannosyl and arabinosyl donors. Here the selectivity is very much related to the conformational restriction and face-discrimination imposed by the cyclic silyl group upon the system.

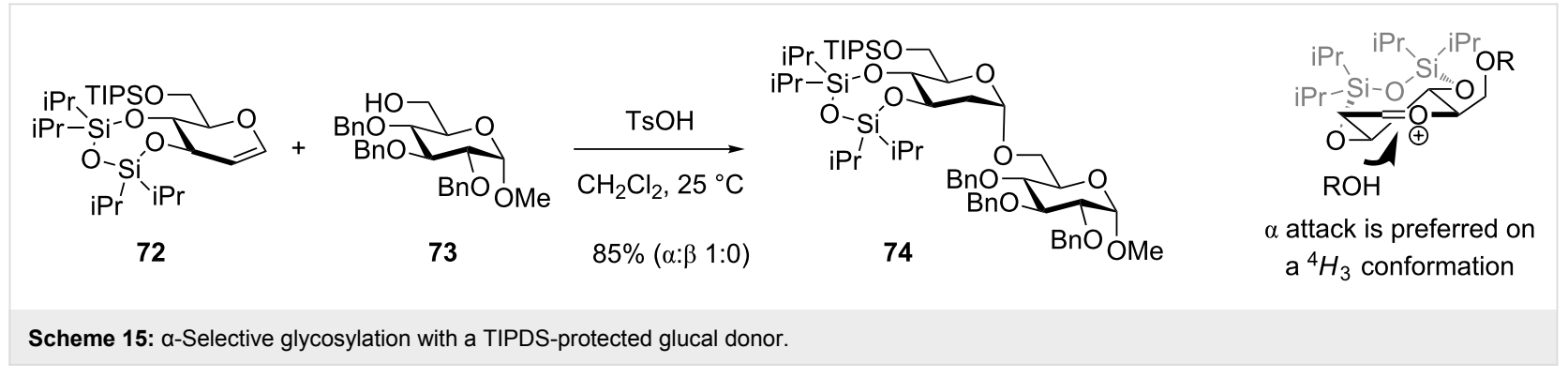




\section{References}

1. Sauer, R. O. J. Am. Chem. Soc. 1944, 66, 1707-1710. doi:10.1021/ja01238a030 See for the first alkyl silyl ethers prepared.

2. Lalonde, M.; Chan, T. H. Synthesis 1985, 817-845. doi:10.1055/s-1985-31361 See for early use as a protective group.

3. Muzart, J. Synthesis 1993, 11-27. doi:10.1055/s-1993-25779

4. Saito, S.; Hirohara, Y.; Narahara, O.; Moriwake, T. J. Am. Chem. Soc. 1989, 111, 4533-4535. doi:10.1021/ja00194a078 See for an early example of conformational restriction of non-carbohydrate ring systems mediated by bulky silyl ethers.

5. Broddefalk, J.; Bergquist, K.-E.; Kihlberg, J. Tetrahedron Lett. 1996, 37, 3011-3014. doi:10.1016/0040-4039(96)00456-X

6. Broddefalk, J.; Bergquist, K.-E.; Kihlberg, J. Tetrahedron 1998, 54, 12047-12070. doi:10.1016/S0040-4020(98)83057-3

7. Myers, A. G.; Liang, J.; Hammond, M. Tetrahedron Lett. 1999, 40, 5129-5133. doi:10.1016/S0040-4039(99)00880-1

8. Myers, A. G.; Glatthar, R.; Hammond, M.; Harrington, P. M.; Kuo, E. Y.; Liang, J.; Schaus, S. E.; Wu, Y.; Xiang, J.-N. J. Am. Chem. Soc. 2002, 124, 5380-5401. doi:10.1021/ja012487x

9. Schindler, C. S.; Bertschi, L.; Carreira, E. M. Angew. Chem., Int. Ed. 2010, 49, 9229-9232. doi:10.1002/anie.201004047

10. Tschamber, T.; Adam, S.; Matsuya, Y.; Masuda, S.; Ohsawa, N.; Maruyama, S.; Kamoshita, K.; Nemoto, H.; Eustache, J. Bioorg. Med. Chem. Lett. 2007, 17, 5101-5106. doi:10.1016/j.bmcl.2007.07.017

11. Valiullina, Z. R.; Khasanova, L. S.; Gimalova, F. A.; Selezneva, N. K.; Spirikhin, L. V.; Miftakhov, M. S. Russ. J. Org. Chem. 2014, 50, 1527-1533. doi:10.1134/S1070428014100194

12. Kopitzki, S.; Dilmaghani, K. A.; Thiem, J. Tetrahedron 2013, 69 , 10621-10636. doi:10.1016/j.tet.2013.10.027

13. Gervay-Hague, J. Acc. Chem. Res. 2016, 49, 35-47. doi:10.1021/acs.accounts.5b00357

14. Schombs, M.; Park, F. E.; Du, W.; Kulkarni, S. S.; Gervay-Hague, J. J. Org. Chem. 2010, 75, 4891-4898. doi:10.1021/j0100366v

15. Kulkarni, S. S.; Gervay-Hague, J. Org. Lett. 2008, 10, 4739-4742. doi:10.1021/ol801780c

16. Hsieh, H.-W.; Schombs, M. W.; Witschi, M. A.; Gervay-Hague, J. J. Org. Chem. 2013, 78, 9677-9688. doi:10.1021/jo4013805

17. Hsieh, H.-W.; Schombs, M. W.; Gervay-Hague, J. J. Org. Chem. 2014, 79, 1736-1748. doi:10.1021/jo402736g

18. Mootoo, D. R.; Konradsson, P.; Udodong, U.; Fraser-Reid, B. J. Am. Chem. Soc. 1988, 110, 5583-5584. doi:10.1021/ja00224a060

19. Zhang, Z. Y.; Ollmann, I. R.; Ye, X.-S.; Wischnat, R.; Baasov, T.; Wong, C.-H. J. Am. Chem. Soc. 1999, 121, 734-753. doi:10.1021/ja982232s

20. Pedersen, C. M.; Marinescu, L. G.; Bols, M. Chem. Commun. 2008, 2465-2467. doi:10.1039/b801305e

21. Jensen, H. H.; Pedersen, C. M.; Bols, M. Chem. - Eur. J. 2007, 13, 7576-7582. doi:10.1002/chem.200700947

22. Heuckendorff, M.; Pedersen, C. M.; Bols, M. Chem. - Eur. J. 2010, 16, 13982-13994. doi:10.1002/chem.201002313

23. Jensen, H. H.; Bols, M. Acc. Chem. Res. 2006, 39, 259-265. doi:10.1021/ar050189p

24. Pedersen, C. M.; Nordstrøm, L. U.; Bols, M. J. Am. Chem. Soc. 2007, 129, 9222-9235. doi:10.1021/ja071955।

25. Heuckendorff, M.; Pedersen, C. M.; Bols, M. J. Org. Chem. 2012, 77 5559-5568. doi:10.1021/jo300591k
26. Hsu, Y.; Lu, X.-A.; Zulueta, M. M. L.; Tsai, C.-M.; Lin, K.-I.; Hung, S.-C.; Wong, C.-H. J. Am. Chem. Soc. 2012, 134, 4549-4552. doi:10.1021/ja300284x

27. Bhat, A. S.; Gervay-Hague, J. Org. Lett. 2001, 3, 2081-2084. doi:10.1021/ol0160405

28. Daly, R.; McCabe, T.; Scanlan, E. M. J. Org. Chem. 2013, 78, 1080-1090. doi:10.1021/jo302487c

29. Liang, X.-Y.; Bin, H.-C.; Yang, J.-S. Org. Lett. 2013, 15, 2834-2837. doi:10.1021/ol401166x

30. Mydock, L. K.; Demchenko, A. V. Org. Biomol. Chem. 2010, 8, 497-510. doi:10.1039/B916088D

31. Mydock, L. K.; Kamat, M. N.; Demchenko, A. V. Org. Lett. 2011, 13, 2928-2931. doi:10.1021/ol2009818

32. Kamkhachorn, T.; Parameswar, A. R.; Demchenko, A. V. Org. Lett. 2010, 12, 3078-3081. doi:10.1021/ol101089u

33. Mydock, L. K.; Demchenko, A. V. Org. Lett. 2008, 10, 2107-2110. doi:10.1021/ol800648d

34. Mydock, L. K.; Demchenko, A. V. Org. Lett. 2008, 10, 2103-2106. doi:10.1021/ol800345j

35. Premathilake, H. D.; Mydock, L. K.; Demchenko, A. V. J. Org. Chem. 2010, 75, 1095-1100. doi:10.1021/jo9021474

36. Crich, D.; Li, M. Org. Lett. 2007, 9, 4115-4118. doi:10.1021/ol701466u

37. Heuckendorff, M.; Premathilake, H. D.; Pornsuriyasak, P.; Madsen, A. Ø.; Pedersen, C. M.; Bols, M.; Demchenko, A. V. Org. Lett. 2013, 15, 4904-4907. doi:10.1021/ol402371b

38. Wang, S.; Meng, X.; Huang, W.; Yang, J.-S. J. Org. Chem. 2014, 79, 10203-10217. doi:10.1021/jo5018684

39. Jensen, H. H.; Nordstrøm, L. U.; Bols, M. J. Am. Chem. Soc. 2004, 126, 9205-9213. doi:10.1021/ja047578j

40. Heuckendorff, M.; Pedersen, C. M.; Bols, M. J. Org. Chem. 2013, 78, 7234-7248. doi:10.1021/jo4012464

41. Pedersen, C. M. Super Armed Glycosyl Donors - The best aid for a better reaction rate \& Radical Azidonation - Novel safe methodologies. Ph.D. Thesis, University of Aarhus, Denmark, 2007.

42. Okada, Y.; Mukae, T.; Okajima, K.; Taira, M.; Fujita, M.; Yamada, H. Org. Lett. 2007, 9, 1573-1576. doi:10.1021/ol070427b

43. Felice, F. D.; Rúveda, E. A.; Stortz, C. A.; Colombo, M. I. Carbohydr. Res. 2013, 380, 167-173. doi:10.1016/j.carres.2013.08.002

44. Hosoya, T.; Ohashi, Y.; Matsumoto, T.; Suzuki, K. Tetrahedron Lett. 1996, 37, 663-666. doi:10.1016/0040-4039(95)02227-9

45. Abe, H.; Terauchi, M.; Matsuda, A.; Shuto, S. J. Org. Chem. 2003, 68, 7439-7447. doi:10.1021/jo030128+

46. Abe, H.; Shuto, S.; Matsuda, A. J. Am. Chem. Soc. 2001, 123, 11870-11882. doi:10.1021/ja011321t

47. Ichikawa, S.; Shuto, S.; Matsuda, A. J. Am. Chem. Soc. 1999, 121, 10270-10280. doi:10.1021/ja992608h

48. Tamura, S.; Abe, H.; Matsuda, A.; Shuto, S. Angew. Chem., Int. Ed. 2003, 42, 1021-1023. doi:10.1002/anie.200390261

49. Romero, J. A. C.; Tabacco, S. A.; Woerpel, K. A. J. Am. Chem. Soc. 2000, 122, 168-169. doi:10.1021/ja993366o

50. Kasai, Y.; Michihata, N.; Nishimura, H.; Hirokane, T.; Yamada, H. Angew. Chem., Int. Ed. 2012, 124, 8150-8153. doi:10.1002/ange. 201203305

51. Yamada, H. Trends Glycosci. Glycotechnol. 2011, 23, 122-133. doi:10.4052/tigg.23.122

52. Heuckendorff, M.; Pedersen, C. M.; Bols, M. J. Org. Chem. 2012, 77, 5559-5568. doi:10.1021/jo300591k

53. Farias, M. A. M.; Kincaid, V. A.; Annamalai, V. R.; Kiessling, L. L. J. Am. Chem. Soc. 2014, 136, 8492-8495. doi:10.1021/ja500622v 
54. Totani, K.; Shinoda, Y.; Shiba, M.; Iwamoto, S.; Koizumi, A.; Matsuzaki, Y.; Hirano, M. RSC Adv. 2015, 5, 75918-75922. doi:10.1039/C5RA16659D

55. Imamura, A.; Ando, H.; Korogi, S.; Tanabe, G.; Muraoka, O.; Ishida, H.; Kiso, M. Tetrahedron Lett. 2003, 44, 6725-6728. doi:10.1016/S0040-4039(03)01647-2

56. Hada, N.; Oka, J.; Nishiyama, A.; Takeda, T. Tetrahedron Lett. 2006, 47, 6647-6650. doi:10.1016/j.tetlet.2006.06.181

57. Gold, H.; Boot, R. G.; Aerts, J. M. F. G.; Overkleeft, H. S.; Codée, J. D. C.; van der Marel, G. A. Eur. J. Org. Chem. 2011, 1652-1663. doi:10.1002/ejoc.201001690

58. Laroussarie, A.; Barycza, B.; Andriamboavonjy, H.; Kenfack, M. T.; Blériot, Y.; Gauthier, C. J. Org. Chem. 2015, 80, 10386-10396. doi:10.1021/acs.joc.5b01823

59. Chen, L.; Kong, F. Tetrahedron Lett. 2003, 44, 3691-3695. doi:10.1016/S0040-4039(03)00673-7

60. Zhu, X.; Kawatkar, S.; Rao, Y.; Boons, G.-J. J. Am. Chem. Soc. 2006, 128, 11948-11957. doi:10.1021/ja0629817

61. Fedina, K. G.; Abronina, P. I.; Podvalnyy, N. M.; Kondakov, N. N.; Chizhov, A. O.; Torgov, V. I.; Kononov, L. O. Carbohydr. Res. 2012, 357, 62-67. doi:10.1016/j.carres.2012.05.021

62. Crich, D.; Pedersen, C. M.; Bowers, A. A.; Wink, D. J. J. Org. Chem. 2007, 72, 1553-1565. doi:10.1021/jo061440x

63. Ishiwata, A.; Akao, H.; Ito, Y. Org. Lett. 2006, 8, 5526-5528. doi:10.1021/ol062198j

64. Abronina, P. I.; Fedina, K. G.; Podvalnyy, N. M.; Zinin, A. I.; Chizhov, A. O.; Kondakov, N. N.; Torgov, V. I.; Kononov, L. O. Carbohydr. Res. 2014, 396, 25-36. doi:10.1016/j.carres.2014.05.017

65. Balmond, E. I.; Benito-Alifonso, D.; Coe, D. M.; Alder, R. W.; McGarrigle, E. M.; Galan, M. C. Angew. Chem. 2014, 126, 8329-8333. doi:10.1002/ange.201403543

66. Dharuman, S.; Crich, D. Chem. - Eur. J. 2016, 22, 4535-4542. doi:10.1002/chem.201505019

67. Furukawa, T.; Hinou, H.; Nishimura, S.-I. Org. Lett. 2012, 14, 2102-2105. doi:10.1021/ol300634x

\section{License and Terms}

This is an Open Access article under the terms of the Creative Commons Attribution License (http://creativecommons.org/licenses/by/4.0), which permits unrestricted use, distribution, and reproduction in any medium, provided the original work is properly cited.

The license is subject to the Beilstein Journal of Organic Chemistry terms and conditions:

(http://www.beilstein-journals.org/bjoc)

The definitive version of this article is the electronic one which can be found at: $\underline{\text { doi:10.3762/bjoc. } 13.12}$ 